\title{
Antiretroviral Therapy Programme Retention and Outcomes after 12 Months in a Retrospective Patient Cohort in Fort Portal, Uganda: The Ongoing Challenge of Male ART Performance
}

\author{
Stefanie Theuring ${ }^{1 *}$, Kizito Mugenyi ${ }^{2 \#}$, John Rubaihayo ${ }^{3}$, Priscilla Busingye ${ }^{2}$ and Gundel Harms ${ }^{1}$ \\ ${ }^{1}$ Institute of Tropical Medicine and International Health, Charité-Universitätsmedizin Berlin, Germany \\ ${ }^{2}$ Virika Hospital, Fort Portal, Uganda \\ ${ }^{3}$ School of Public Health, Mountains of the Moon University, Fort Portal, Uganda \\ \#Author deceased last year
}

\begin{abstract}
Background: Antiretroviral therapy (ART) programmes have been extensively scaled-up in countries like Uganda. While success of these programmes largely depends on lasting patient retention, attrition rates are often especially high in the first year after treatment initiation. Our study aimed at analysing recent data of a Ugandan ART patient cohort regarding 12 months ART outcomes and programme retention.
\end{abstract}

Methods: Virika Hospital in Fort Portal, Western Uganda, is offering ART services according to national treatment standards. A routinely collected patient monitoring database was used for retrospective analysis, following-up 369 patients for 12 months after enrolment. Primary outcome indicator was 12 months retention (being alive and active in programme). We assessed clinical ART progress, attrition, mortality and influencing factors, particularly gender differences.

Results: From 369 ART patients, two-thirds were female. Overall ART outcomes and adherence in this cohort were satisfying, but in men, improvement of CD4-cell counts and weight gain after 12 months were significantly lower than in female patients. In total, one in eight patients $(12.2 \%)$ was subject to all-cause attrition after 12 months. We identified low CD4-cell count at ART enrolment as the only independent risk factor for attrition after 12 months $(p=0.037)$, while male patients were at highest risk for this, showing significantly lower CD4-cell counts at ART initiation $(p=0.008)$.

Conclusion: We found overall outcomes of this ART programme encouraging, however, attention must be paid particularly to male ART patients. Men were underepresented in our cohort, enrolled in the ART programme at later disease stage, and showed worse ART outcomes after 12 months. Our data suggests that the known challenge of male ART performance is persisting, and that it has not sufficiently been addressed in the past years. Especially the problem of male late-presenters in ART programmes should lead to action in health services planning and implementation, for example by offering more HIV testing opportunities to men.

Keywords: HIV; ART; Outcomes; Retention; Attrition; Gender differences; Uganda

\section{Introduction}

After more than a decade of establishing and expanding programmes for HIV prevention and treatment, the fight against HIV seems to have reached a turning point in most generalised epidemic settings in sub-Saharan Africa. While in 2002, just about 300.000 HIV-infected individuals received antiretroviral treatment (ART) in low- and middle income countries, and 2 million deaths were attributed to AIDS, the number of ART patients has grown to 9.7 million by the end of 2012, and AIDS-related deaths have decreased to about 1.6 million [1].

Also in highly HIV-burdened countries like Uganda, the magnitude of the epidemic has been reduced to a large extent in the past decades; yet, there is no reason to relax: after HIV prevalence in the age group $15-49$ had reached a low of $6.4 \%$ in Uganda in 2005, it increased to $7.3 \%$ by 2011 [2], and 1.4 million Ugandan people living with HIV/AIDS demonstrate that this incurable disease is still posing one of the biggest health challenges to the country [3]. In 2012, 62\% of Ugandan men and women in advanced HIV disease stage had access to ART, signifying that the country still has some way to go to achieve the national target of providing antiretroviral drugs to $80 \%$ of the population in need by 2015 [4].

Overall, still too many HIV-infected people suffer and die despite available and affordable treatment options. In as many as three quarters of sub-Saharan African people living with HIV, sustained viral suppression is not achieved [1]. This is partly a consequence of gaps in the treatment cascade, including early HIV diagnosis and linkage to care, but also a consequence of patient attrition, which is usually especially high in the first 12 months of ART initiation [5,6]. In Uganda, ART attrition rates after 12 months have been reported to reach up to $20 \%$ [7], while generally, among ART patients who are subject to attrition, i.e. who are lost to follow-up (LTFU), it is estimated that $40-60 \%$ are dead $[6,8]$. Among factors influencing patient attrition, particularly gender aspects have often been debated in the context of ART programme planning in the past years, but findings have been inconsistent and require verification for specific regional settings.

*Corresponding author: Stefanie Theuring, Institute of Tropical Medicine and International Health, Charité- Universitätsmedizin, Campus Virchow-Klinikum Augustenburger Platz 1, 13353 Berlin; Tel: +49 30450565 725; Fax: +49 304507 565 725; E-mail: stefanie.theuring@charite.de

Received October 25, 2014; Accepted January 20, 2015; Published January 28, 2015

Citation: Theuring S, Mugenyi K, Rubaihayo J, Busingye P, Harms G (2015) Antiretroviral Therapy Programme Retention and Outcomes after 12 Months in a Retrospective Patient Cohort in Fort Portal, Uganda: The Ongoing Challenge of Male ART Performance. J AIDS Clin Res 6: 423. doi:10.4172/2155-6113.1000423

Copyright: (C) 2015 Theuring S, et al. This is an open-access article distributed under the terms of the Creative Commons Attribution License, which permits unrestricted use, distribution, and reproduction in any medium, provided the original author and source are credited. 
Citation: Theuring S, Mugenyi K, Rubaihayo J, Busingye P, Harms G (2015) Antiretroviral Therapy Programme Retention and Outcomes after 12 Months in a Retrospective Patient Cohort in Fort Portal, Uganda: The Ongoing Challenge of Male ART Performance. J AIDS Clin Res 6 : 423. doi:10.4172/2155-6113.1000423

It is crucial to identify factors impeding ART programme retention and success, in order to design appropriate mechanisms to reduce mortality and attrition especially in the first year of ART. The aim of our study was to assess early ART outcomes in a current real-life setting in Western Uganda by analysing data of a retrospective patient cohort from Virika Hospital, Fort Portal, and thereby generate relevant insights for effective ART programme implementation.

\section{Methods}

\section{Study setting}

The Western Region of Uganda represents a rural, structurally limited study setting, where the nationwide HIV prevalence of $7.3 \%$ among the age group 15-49 is slightly exceeded with an estimated prevalence of $8.2 \%$ [2]. Virika Hospital is a catholic diocese hospital in Fort Portal, Western Uganda. Virika Hospital has been running an AIDS care and treatment (ACT) programme for almost a decade with support of the PEPFAR- funded AIDSRelief Uganda and the Ugandan Catholic Medical Bureau (UCMB).

The following standard procedures are applied in Virika Hospital's ACT programme: Voluntary HIV counselling and testing is offered to all in- and out patients and to the population served by the hospital. Persons diagnosed HIV-positive are asked to register immediately in the ART clinic to be checked for their clinical condition and treatment options. Patients are then assessed for eligibility for ART and counselled and trained on adherence. First-line treatment regimens, according to WHO standard recommendations, include a combination of "FTC/TDF/NVP or EFV", or, according to Uganda's national recommendation [9], a combination of "EFV/FTC/TDF"or "3TC/AZT/ NVP or EFV". After treatment start, patients are required to approach the clinic for clinical screening and drug refills monthly or every second month once having stabilized. In case of treatment failure or severe side effects, options for regimen change are evaluated. Patients missing their drug refill appointment are generally contacted. After 3 months of no return to the clinic, a patient is defined as lost to follow-up (LTFU). The service is free of charge.

\section{Data collection and analysis}

Since the start of Virika Hospital's ART clinic in 2005, an extensive patient dataset had been created to inform the ACT programme and AIDSRelief/UCMB on its progress and success. To collect the data, ART clinic staff systematically registered ART patients' background and progress in specific forms at each clinic visit. The forms were transformed into a database by data managers of Virika Hospital using IQCare, a free software package for electronic medical recording developed by Futures Groups International/AIDS Relief Uganda.

Selected relevant data for this assessment was extracted from the overall IQCare database and transferred into a new dataset for analysis. Our extracted dataset included all eligible ART patients who had started ART between January 2010 and March 2012. We did not include patients with treatment start before January 2010, because standard ART procedures were not always comparable at earlier times. Followup data was available until March 2013, allowing ART progress followup (including death or LTFU) until the primary endpoint of 12 months after ART initiation in all patients.

To assure comparability among patients, we excluded data of ART patients $<18$ years of age, as well as patients who were pregnant at enrolment in the ART clinic, as those received antiretroviral drugs in ANC services. Female patients who had already started ART, but got pregnant at a later point in the follow-up period however remained in the cohort, because they continued to receive ART within the ART clinic.

Available information was evaluated at three points in time: enrolment/ART start (baseline data on sociodemographic, economic and clinical background), and follow-up visits after 6 and 12 months measuring ART progress parameters including CD4-cell count, weight development, emergence of opportunistic infections (OIs), and adherence levels. Adherence levels were indicated in percentage categories of: $>95 \%, 75 \%-95 \%$, and $<75 \%$ based on patients' selfreported correct pill intake in the past month.

Primary outcome indicator was 12 months ART retention (alive and active in programme). In patients not meeting ART retention, we looked for differences between confirmed death cases and cases LTFU for unknown reason (including factors like unreported death, treatment delay $>3$ months, and treatment exit).

For data analysis, the extracted dataset was transferred into PASW 18. We performed descriptive analysis for baseline data and differentiated by sex using $\mathrm{Chi}^{2}$ or Fisher's Exact test and Mann-Whitney-U test for metric variables. To check for differences at two points in time in paired samples, Wilcoxon Sign Ranks test was used. Odds ratios (ORs) were calculated to identify risk factors for ART retention. For multivariate analysis, variables showing significant influence in univariate analysis were included into logistic regression to calculate adjusted odds ratios (AORs).

The data used in this study had been collected for the purpose of routine programme evaluation on behalf of Virika Hospital and the UCMB. Retrospective analysis of the data for operational research was approved by Virika Hospital board, the UCMB and Futures Group/ AIDS Relief Uganda. All data was processed strictly anonymously and treated confidential.

\section{Results}

\section{Study cohort}

In the time period between January 2010 and March 2012, 369 HIVpositive study-eligible individuals had started ART in Virika Hospitals ACT programme. Among these, two thirds (65.3\%) of the patients were female, and one third (34.7\%) was male.

Baseline information for all cohort members at ART enrolment, as well as sex-segregated differences in univariate analysis, are presented in Table 1. Significant differences between male and female clients were found in male ART patients being older than female patients; they were more likely to be married, to have more children $<15$ years of age living in their household, and to be formally employed. Male patients had a significantly lower CD4-cell count at ART start. Apart from sex, no other sociodemographic factor was found to be linked to lower CD4-cell counts at ART start. In male patients, less time had passed between their ART registration and ART start. All patients but one received an ART regimen recommended as first line regimen by Ugandan government or WHO.

At ART enrolment, 161/369 patients (43.6\%) were started on cotrimoxazole to prevent OIs. Initiation on cotrimoxazole at ART enrolment was significantly linked to presentation with an OI at this point $(\mathrm{p}=0.019)$. Presentation of an active OI at ART enrolment was recorded in $24 / 369$ patients $(6.5 \%)$. 
Citation: Theuring S, Mugenyi K, Rubaihayo J, Busingye P, Harms G (2015) Antiretroviral Therapy Programme Retention and Outcomes after 12 Months in a Retrospective Patient Cohort in Fort Portal, Uganda: The Ongoing Challenge of Male ART Performance. J AIDS Clin Res 6 : 423. doi:10.4172/2155-6113.1000423

Page 3 of 7

\begin{tabular}{|c|c|c|c|c|}
\hline Variable & Total cohort & Female & Male & P-level \\
\hline $\begin{array}{l}\text { Sex }(\mathrm{n}=369) n(\%) \\
\text { Female } \\
\text { Male }\end{array}$ & $\begin{array}{l}241(65.3 \%) \\
128(34.7 \%)\end{array}$ & & & \\
\hline Age $(n=369)$ median (range) & 32 years $(18-75)$ & 29 years & 36 years & $<0.001^{*}$ \\
\hline $\begin{array}{l}\text { Education }(\mathrm{n}=345) n(\%) \\
\text { No school education } \\
\text { School education } \\
\qquad \quad \text { Primary } \\
\bullet \quad \text { Secondary } \\
\bullet \quad \text { Above Secondary }\end{array}$ & $\begin{array}{c}89(25.8 \%) \\
256(74.2 \%) \\
192(55.6 \%) \\
54(15.7 \%) \\
10(2.9 \%)\end{array}$ & $\begin{array}{c}64(28.4 \%) \\
161(71.6 \%) \\
121(53.8 \%) \\
37(16.4 \%) \\
3(1.3 \%)\end{array}$ & $\begin{array}{l}25(20.8 \%) \\
95(79.2 \%) \\
71(59.2 \%) \\
17(14.2 \%) \\
7(5.8 \%)\end{array}$ & $0.124^{\circ}$ \\
\hline $\begin{array}{l}\text { Marital Status }(\mathrm{n}=363) n(\%) \\
\text { Married } \\
\text { Single/widowed/divorced }\end{array}$ & $\begin{array}{l}191(52.6 \%) \\
172(47.4 \%)\end{array}$ & $\begin{array}{l}107(45 \%) \\
131(55 \%)\end{array}$ & $\begin{array}{l}84(67.2 \%) \\
41(32.8 \%)\end{array}$ & $<0.001^{\circ}$ \\
\hline $\begin{array}{l}\text { Literacy Level }(n=342) n(\%) \\
\text { Literate } \\
\text { Illiterate }\end{array}$ & $\begin{array}{l}132(38.6 \%) \\
210(61.4 \%)\end{array}$ & $\begin{array}{c}79(35.6 \%) \\
143(64.4 \%)\end{array}$ & $\begin{array}{l}53(44.2 \%) \\
67(55.8 \%)\end{array}$ & $0.120^{\circ}$ \\
\hline $\begin{array}{l}\text { Employment status }(\mathrm{n}=367) n(\%) \\
\text { Official employment } \\
\text { Unemployed/self-employed }\end{array}$ & $\begin{array}{c}83(22.6 \%) \\
284(77.4 \%)\end{array}$ & $\begin{array}{c}46(19.2 \%) \\
193(80.8 \%)\end{array}$ & $\begin{array}{l}37(28.9 \%) \\
91(71.1 \%)\end{array}$ & $0.035^{\circ}$ \\
\hline $\begin{array}{l}\text { HIV status disclosure }(\mathrm{n}=358) n(\%) \\
\text { Yes } \\
\text { No }\end{array}$ & $\begin{array}{l}326(91.1 \%) \\
32(8.9 \%)\end{array}$ & $\begin{array}{l}209(89.3 \%) \\
28(10.7 \%)\end{array}$ & $\begin{array}{l}117(94.4 \%) \\
\quad 7(5.6 \%)\end{array}$ & $0.112^{\circ}$ \\
\hline $\begin{array}{l}\text { Member of HIV support group }(\mathrm{n}=302) n(\%) \\
\text { Yes } \\
\text { No }\end{array}$ & $\begin{array}{c}7(2.3 \%) \\
295(97.7 \%)\end{array}$ & $\begin{array}{c}6(3.0 \%) \\
195(97.0 \%)\end{array}$ & $\begin{array}{c}1(1.0 \%) \\
100(99.0 \%)\end{array}$ & $0.431^{\wedge}$ \\
\hline $\begin{array}{l}\text { Self-reported alcohol abuse }(\mathrm{n}=369) n(\%) \\
\text { Yes } \\
\text { No }\end{array}$ & $\begin{array}{c}10(2.7 \%) \\
359(97.3 \%)\end{array}$ & $\begin{array}{c}4(1.7 \%) \\
233(98.3 \%)\end{array}$ & $\begin{array}{c}6(4.7 \%) \\
122(95.3 \%)\end{array}$ & $0.102^{\wedge}$ \\
\hline $\begin{array}{l}\text { Number of children<15 living in the household }(\mathrm{hh})(\mathrm{n}=369) \\
\text { median (range) }\end{array}$ & $2(0-17)$ & $2(0-11)$ & $3(0-17)$ & $0.039^{*}$ \\
\hline Time travelled to hospital $(\mathrm{n}=338)$ median (range) & $\begin{array}{l}45 \text { minutes } \\
(0-240)\end{array}$ & 60 minutes $(0-240)$ & 30 minutes $(0-180)$ & $0.147^{*}$ \\
\hline Time from diagnosis to ART start $n=222$ median (range) & 501 days $(0-7187)$ & 561 days $(0-7187)$ & 310 days $(17-6547)$ & $0.121^{*}$ \\
\hline Time from diagnosis to registration $(\mathrm{n}=226)$ median (range) & 20.5 days $(0-7187)$ & 28 days $(0-7178)$ & 15 days $(0-6531)$ & $0.250^{*}$ \\
\hline Time from registration to ART start $n=348$ median (range) & 264.5 days $(0-2237)$ & 369 days $(0-2030)$ & 116 days $(0-2237)$ & $0.005^{*}$ \\
\hline $\begin{array}{l}\text { CD4 count at enrolment }(\mathrm{n}=301) \text { median (range) } \\
\text { - With children in } \mathrm{hh}(\mathrm{n}=166) \\
\text { CD4 count }<100 \text { cells } / \mathrm{mm}^{3} n(\%) \\
\text { CD4 count } \geq 100 \text { cells } / \mathrm{mm}^{3} n(\%)\end{array}$ & $\begin{array}{c}287 \text { cells } / \mathrm{mm}^{3}(9-908) \\
\\
31(10.3 \%) \\
270(89.7 \%)\end{array}$ & $\begin{array}{c}302 \text { cells } / \mathrm{mm}^{3}(36-908) \\
299 \mathrm{cells} / \mathrm{mm}^{3} \\
308 \mathrm{cells} / \mathrm{mm}^{3} \\
14(7.1 \%) \\
182(92.9 \%)\end{array}$ & $\begin{array}{l}257 \text { cells } / \mathrm{mm}^{3}(9-681) \\
\\
17(16.2 \%) \\
88(83.8 \%)\end{array}$ & $\begin{array}{l}\mathbf{0 . 0 0 8 ^ { * }} \\
0.834^{*} \\
\mathbf{0 . 0 1 4}^{\circ}\end{array}$ \\
\hline $\begin{array}{l}\text { WHO stage at ART start }(\mathrm{n}=369) n(\%) \\
\text { I or II } \\
\text { III or IV }\end{array}$ & $\begin{array}{l}191(51.8 \%) \\
178(48.2 \%)\end{array}$ & $\begin{array}{l}130(53.9 \%) \\
111(46.1 \%)\end{array}$ & $\begin{array}{l}61(47.7 \%) \\
67(52.3 \%)\end{array}$ & $0.250^{\circ}$ \\
\hline $\begin{array}{l}\text { Any barrier named for adherence }(n=309) \\
\text { Yes } \\
\text { No }\end{array}$ & $\begin{array}{l}117(37.9 \%) \\
192(62.1 \%)\end{array}$ & $\begin{array}{c}82(40.2 \%) \\
122(59.8 \%)\end{array}$ & $\begin{array}{l}35(33.3 \%) \\
70(66.7 \%)\end{array}$ & 0.239 \\
\hline
\end{tabular}

${ }^{*}$ Mann-Whitney-U-Test

${ }^{\circ} \mathrm{Chi}{ }^{2}$-Test

${ }^{\wedge}$ Fisher's Exact Test

Table 1: Baseline characters of the cohort at enrolment in ART, total and sex-segregated.

\section{Progress of ART over 12 months}

Between baseline, 6 months and 12 months visit, CD4-cell counts showed statistically highly significant increases for the overall cohort. However, the changes differed according to sex. As shown in table 2, CD4-cell improvement stagnated in the male subcohort between 6 and 12 months. CD4-cell counts after 12 months were still significantly higher in women (median 426 vs. 372 cells $/ \mathrm{mm}^{3}$ in men, $\mathrm{M}-\mathrm{W}-\mathrm{U} \mathrm{p}=$ 0.035 ). The median cohort weight (excluding women who had gotten pregnant by 6 or 12 months) also increased between baseline, 6 and 12 months. When separating by sex, again in the male subcohort the overall weight gain stagnated after 6 months (Table 2).

Adherence levels were high at 6 months, with only 6/322 (1.8\%) patients stating that they had achieved $\leq 95 \%$ drug adherence, and 316 patients $(98.2 \%)$ stating $>95 \%$ adherence. This rate slightly declined over time, with $95.6 \%$ reporting $>95 \%$ adherence after 12 months of ART. For the entire time period until 12 months, $93.8 \%$ reported $>95 \%$ adherence. Patients with lower CD4-cell count at ART enrolment were significantly more likely to show $>95 \%$ drug adherence throughout the first 12 months of treatment compared to patients with higher CD4-cell counts at enrolment (median baseline 319 cells $/ \mathrm{mm}^{3}$ vs. $501 \mathrm{cells} / \mathrm{mm}^{3}$; $\mathrm{M}-\mathrm{W}-\mathrm{U} \mathrm{p}=0.022$ ). Associations to other sociodemographic, economic or clinical factors were not statistically relevant.

After 6 months of ART, an increase of active OI was reported from 24 cases at baseline (6.5\%) to 25 cases (7.5\%), after 12 months, active OI was found in 35 (10.8\%) of surviving patients. Presence of active OI at 12 months had no association to previous CD4-cell counts or wheather or not cotrimoxazole was initiated at ART initiation. Cotrimoxazole 
Citation: Theuring S, Mugenyi K, Rubaihayo J, Busingye P, Harms G (2015) Antiretroviral Therapy Programme Retention and Outcomes after 12 Months in a Retrospective Patient Cohort in Fort Portal, Uganda: The Ongoing Challenge of Male ART Performance. J AIDS Clin Res 6 : 423. doi:10.4172/2155-6113.1000423

Page 4 of 7

\begin{tabular}{|c|c|c|c|c|c|}
\hline Variable & Baseline value & $6 \mathrm{~m}$ outcome & $\begin{array}{c}\text { P-Level } \\
\text { Baseline-6m }\end{array}$ & $12 \mathrm{~m}$ outcome & $\begin{array}{l}\text { P-Level }{ }^{\S} \\
6 m-12 m\end{array}$ \\
\hline $\begin{array}{cl}\text { CD4-cell count (median) } \\
\bullet \quad \text { Female } \\
\bullet \quad \text { Male }\end{array}$ & $\begin{array}{c}287 \text { cells } / \mathrm{mm}^{3} 301 \text { cells/ } \\
\mathrm{mm}^{3} \\
257 \mathrm{cells} / \mathrm{mm}^{3}\end{array}$ & $\begin{array}{l}381 \text { cells } / \mathrm{mm}^{3} \\
381 \text { cells } / \mathrm{mm}^{3} \\
386 \text { cells } / \mathrm{mm}^{3}\end{array}$ & $\begin{array}{l}<0.001 \\
<0.001 \\
<0.001\end{array}$ & $\begin{array}{l}396 \text { cells } / \mathrm{mm}^{3} \\
426 \text { cells } / \mathrm{mm}^{3} \\
372 \text { cells } / \mathrm{mm}^{3}\end{array}$ & $\begin{array}{l}0.013 \\
0.006 \\
0.717\end{array}$ \\
\hline $\begin{array}{cc}\text { Weight } & \text { (median) } \\
\bullet \quad & \text { Female } \\
\bullet & \text { Male }\end{array}$ & $\begin{array}{l}55 \mathrm{~kg} \\
53 \mathrm{~kg} \\
56 \mathrm{~kg}\end{array}$ & $\begin{array}{l}55 \mathrm{~kg} \\
54 \mathrm{~kg} \\
59 \mathrm{~kg}\end{array}$ & $\begin{array}{l}\mathbf{0 . 0 0 1} \\
0.086 \\
\mathbf{0 . 0 0 1}\end{array}$ & $\begin{array}{l}56 \mathrm{~kg} \\
55 \mathrm{~kg} \\
59 \mathrm{~kg}\end{array}$ & $\begin{array}{l}\mathbf{0 . 0 0 4} \\
\mathbf{0 . 0 0 1} \\
0.719\end{array}$ \\
\hline
\end{tabular}

§Wilcoxon Signed Ranks Test

Table 2: ART progress until 12 months: CD4-cell counts and weight gain, total and sex-segregated.

intake at 6 months increased to $188 / 333$ patients (56.5\%) and after 12 months to $234 / 326$ patients $(71.8 \%)$.

\section{Retention within the first 12 months of ART}

After 6 months, 336 patients out of 369 (91.1\%) were still alive and active in the programme, while $33(8.9 \%)$ were reported LTFU or dead. After 12 months, 324 patients (87.8\%) were still alive and active in the programme, while 45 (12.2\%) were reported LTFU or dead.

In univariate analysis, we identified male sex and CD4-cell count $<100$ cells $/ \mathrm{mm}^{3}$ at enrolment as risk factors for death or LTFU at 12 months. After multivariate analysis, CD4-cell count $<100$ cells $/ \mathrm{mm}^{3}$ at enrolment remained the only risk factor with independent statistical significance $(p=0.037)$. Other sociodemographic, economic or clinical factors were not found to be linked to 12 month programme retention (Table 3).

We split attrition by confirmed death cases and LTFU for unknown reasons. After 6 months, the dataset included 8 confirmed death cases $(2.2 \%)$, while after 12 months, there were 14 confirmed death cases (3.8\%). Separating influencing factors for non-retention in ART by those confirmed death cases and LTFU cases, it turned out that confirmed death after 12 months was significantly associated with low CD4-cell counts at the beginning of ART (86 vs 289 cells $/ \mathrm{mm}^{3}$, MWU 0.014 ). While $2.9 \%$ of the female patients had died within 12 months, this rate was almost double as high among male patients with $5.5 \%$; however, according to the overall low number of death cases, this association had no statistical significance (Fisher's exact test $\mathrm{p}=0.256$ ).

Patients LTFU for unknown reasons after 12 months $(n=31)$ had not presented with a significantly different baseline CD4-cell count compared to retained patients ( $301 \mathrm{vs.} 288 \mathrm{cells} / \mathrm{mm}^{3}, \mathrm{MWU} \mathrm{p}=0.908$ ). While $6.4 \%$ of female patients were LTFU for unknown reasons after 12 months, the rate again almost doubled in male patients $(12.4 \%$, $\mathrm{Chi}^{2} \mathrm{p}=0.053$ ). Patients having named any barrier (including financial,

\begin{tabular}{|c|c|c|c|c|c|c|}
\hline Factor & $\begin{array}{l}\% \text { alive/ active } \\
\text { in programme } \\
\text { at } 12 \mathrm{~m}\end{array}$ & OR & $\mathrm{Cl}(95 \%)$ & $\mathbf{p}$ & AOR & $p$ \\
\hline $\begin{array}{l}\text { Sex }(n=369) \\
\text { Male } \\
\text { Female }\end{array}$ & $\begin{array}{c}82 \\
90.9\end{array}$ & $\begin{array}{l}1.000 \\
2.181 \\
\end{array}$ & $1.162-4.090$ & 0.014 & $\begin{array}{l}1.000 \\
1.446\end{array}$ & 0.347 \\
\hline $\begin{array}{l}\text { Age at enrolment }(n=369) \\
\geq 30 \text { years } \\
<30 \text { years }\end{array}$ & $\begin{array}{l}86.2 \\
90.4\end{array}$ & $\begin{array}{l}1.000 \\
1.503\end{array}$ & $0.770-2.934$ & 0.23 & & \\
\hline $\begin{array}{l}\text { Marital status }(n=363) \\
\text { Married } \\
\text { Not married }\end{array}$ & $\begin{array}{l}90.6 \\
84.9\end{array}$ & $\begin{array}{l}1.000 \\
0.584\end{array}$ & $0.308-1.108$ & 0.097 & & \\
\hline $\begin{array}{l}\text { Education }(n=345) \\
\text { At least primary school } \\
\text { No school education }\end{array}$ & $\begin{array}{l}87.5 \\
89.9\end{array}$ & $\begin{array}{l}1.000 \\
1.270\end{array}$ & $0.581-2.777$ & 0.549 & & \\
\hline $\begin{array}{l}\text { Employment status }(\mathrm{n}=367) \\
\text { Unemployed } \\
\text { Officially employed }\end{array}$ & $\begin{array}{l}87.3 \\
89.2\end{array}$ & $\begin{array}{l}1.000 \\
1.194\end{array}$ & $0.550-2.591$ & 0.654 & & \\
\hline $\begin{array}{l}\text { Any adherence barriers named at } \\
\text { enrollment }(n=309) \\
\text { No } \\
\text { Yes }\end{array}$ & $\begin{array}{l}90.1 \\
82.9\end{array}$ & $\begin{array}{l}1.000 \\
0.533\end{array}$ & $0.261-1.046$ & 0.078 & & \\
\hline $\begin{array}{l}\text { Travelling time to } \mathrm{HF}(\mathrm{n}=338) \\
\geq 45 \mathrm{~min} \\
<45 \mathrm{~min}\end{array}$ & $\begin{array}{l}90.9 \\
85.3\end{array}$ & $\begin{array}{l}1.000 \\
0.583\end{array}$ & $0.298-1.142$ & 0.112 & & \\
\hline $\begin{array}{l}\text { Status disclosure }(n=358) \\
\text { Yes } \\
\text { No }\end{array}$ & $\begin{array}{l}86.5 \\
96.9\end{array}$ & $\begin{array}{l}1.000 \\
4.837\end{array}$ & $0.644-36.335$ & $0.156^{\wedge}$ & & \\
\hline $\begin{array}{l}\text { Alcohol abuse }(n=369) \\
\text { Yes } \\
\text { No }\end{array}$ & $\begin{array}{c}70 \\
88.3\end{array}$ & $\begin{array}{l}1.000 \\
3.235\end{array}$ & $0.805-12.990$ & $0.11^{\wedge}$ & & \\
\hline $\begin{array}{l}\text { CD4 cell count at enrolment }(n=301) \\
\geq 100 \text { cells } / \mathrm{mm}^{3} \\
<100 \text { cells } / \mathrm{mm}^{3}\end{array}$ & $\begin{array}{l}91.1 \\
77.4\end{array}$ & $\begin{array}{l}1.000 \\
0.334\end{array}$ & $0.131-0.857$ & $0.027^{\wedge}$ & $\begin{array}{l}1.000 \\
0.362\end{array}$ & 0.037 \\
\hline $\begin{array}{l}\text { OI present at enrolment }(n=369) \\
\text { Yes } \\
\text { No }\end{array}$ & $\begin{array}{l}79.2 \\
88.4\end{array}$ & $\begin{array}{l}1.000 \\
2.007\end{array}$ & $0.710-5.670$ & $0.193^{\wedge}$ & & \\
\hline
\end{tabular}

$\wedge=$ Fisher's exact test, all other: $\mathrm{Chi}^{2}$ test 
Citation: Theuring S, Mugenyi K, Rubaihayo J, Busingye P, Harms G (2015) Antiretroviral Therapy Programme Retention and Outcomes after 12 Months in a Retrospective Patient Cohort in Fort Portal, Uganda: The Ongoing Challenge of Male ART Performance. J AIDS Clin Res 6 : 423. doi:10.4172/2155-6113.1000423

transport-related or social) for adherence at ART enrolment were also more likely to be LTFU after 12 months ( $12.5 \%$ vs. $\left.5.4 \%, \mathrm{Chi}^{2} \mathrm{p}=0.031\right)$.

\section{Discussion}

In our analysis of a retrospective Ugandan ART patient cohort with regards to 12 month programme outcomes, we found encouraging overall retention rates and ART progress. However, male patients were underrepresented in this ART clinic, showed worse health conditions at ART start and, consequently, less favourable programme outcomes after 12 months than female patients. Our findings reinforce previous results of other studies on ART outcomes [10-15], leading to the assumption that the persisting challenge of male ART performance has not sufficiently been addressed by ART implementers in the past years.

Sociodemographic baseline information of our cohort differed between male and female patients. Male patients were older, more likely to be married and officially employed, had more children living at home, lower CD4-cell counts and less time having passed between ART registration and ART start. These sex-specific differences are in compliance with a similar patient cohort from the same region in Uganda [10].

Long delay between clinic registration and ART start is partly assumed to be a consequence of general health system shortcomings, like overburdened services with long waiting times, or drug shortages. Unsuccessful conduction of the obligatory ART-preceding adherence training could also have contributed to time gaps. At the same time, patients with a relatively good health condition might adopt the attitude that ART start can be postponed if they are still feeling healthy. The finding that male patients experienced less time to pass between ART registration and ART start was very likely an effect of their worse clinical condition regarding CD4-cell counts at that point. ART programme implementers should aim at reducing the delay in treatment initiation by close follow-up of patients once they have been registered at ART services, and by minimising health system barriers.

Our cohort consisted of roughly one third of men and two thirds of women, or a male to female ratio of 1:1.88. For HIV prevalence in the mid-Western Region of Uganda, the UAIS report of 2011 stated a male to female ratio of $1: 1.28$, so the difference can not be explained by an overall higher female prevalence alone. [2] It has been observed in other studies before that men are less represented in treatment programmes than women [10-13]. According to UNAIDS, in 2012, $57 \%$ of treatment-eligible men received ART in low and middle income countries, compared to $73 \%$ of treatment-eligible women [1]. A reason for the disproportionate sex distribution might be found in the fact that female health issues have been a predominant target of public health efforts in the past years, and also in the fact that women are routinely attending health services when they get pregnant, and thus can be accessed for HIV testing and ART provision more easily than men [13$15]$.

This has also been discussed as an explanation for women enrolling into ART services at earlier disease stages than men, as frequently described in previous studies $[10,11,16]$. Generally, in low- and middleincome countries, one in four people who initiate ART present at late disease stage with CD4-cell counts below 100 cells $/ \mathrm{mm}^{3}$ [1]. In our cohort, this was the case only for every tenth patient, but the male rate was more than twice as high as the female rate. These predominantly male late-presenters have a much higher risk of treatment failure and death, as confirmed by our results: CD4-cell count below 100 cells $/ \mathrm{mm}^{3}$ at enrolment was the only independent risk factor for death or LTFU after 12 months. Other studies accordingly identified low CD4-cell counts as the strongest predictor of mortality [17].

We tried to verify the commonly suggested causal chain of preceding pregnancy leading to earlier ART initiation in female patients, hypothesising that this would reversely condense in later ART start in childless women. However, in our cohort, childless women had equally high CD4-cell counts at ART start as women with children. This insinuates that women's earlier treatment start is not only related to pregnancy healthcare structures, but that there might also be other, sociobehavioural differences in seeking healthcare between male and female patients [18]. More research is required here, to fully understand this gap in the timing of ART initiation.

Yet, indisputably, reproductive health services focus on girls and women more than on men and offer multiple possibilities of testing women's HIV status, which their male counterparts might not find so easily. Hence, delayed HIV diagnosis and treatment often results from lack of male access to testing, and there is a pressing need to discuss how testing facilities and opportunities can be made more widely available outside of reproductive health services $[16,19]$. Sekandi et al. showed that door-to-door home-based testing is acceptable and feasible and can increase the reach of HIV testing services in Uganda [20]. Since confidentiality and stigma issues seem to be among major obstacles for male utilisation of testing services [19], it could also be worthwhile to consider the novel approach of selftesting using oral fluid rapid diagnostic tests, for which high acceptability and accuracy has been found in a Malawian pilot study by Choko et al. [21]. Selftesting approaches might break with some longstanding norms and assumptions surrounding HIV testing [1], but they could have a groundbreaking effect on HIV status knowledge and linkage to care in regions where accessability and utilisation of facility-based testing are limited especially for men. Further research in this field is urgently required to evaluate the potential of this new approach.

In our study cohort, the overall clinical condition with regards to CD4-cell counts had improved after 12 months, similar to other evaluated ART cohorts [11]. Women had a better immunologic response then men regarding CD4-cell count increase, confirming the finding from a multicenter cohort study from South Africa [12]. Notably, improvement of CD4-cell counts as well as overall weight gain stagnated after 6 months in the male subcohort. It has been described elsewhere that drug adherence is significantly influencing CD4-cell count increase and that adherence is often worse in men as compared to women $[11,22]$, so it could be speculated that also in our cohort, men might have been less adherent, thereby impeding treatment success. However, we were not able to assess sex differences in adherence in our analysis because of the small number of patients reporting adherence rates below 95\%. Besides that, the overall high adherence rates in this cohort give reason to take a reporting bias into account. Pill counts were unfortunately not routinely performed in this ART clinic to triangulate self-reported adherence percentages. However, in a similar Ugandan survey, adherence rates of ART patients measured through pill counts were also reported very high at $98 \%$ [10]. Social, financial or transport-related adherence barriers were mentioned by about a third of all patients, with no difference between male and female patients. Considering that mentioning adherence barriers was associated with being LTFU after 12 months, it seems an important step for programme implementers to further analyse ways to overcome those specific barriers, e.g. by establishing transport reimbursement systems.

Possible biologic sex differences e.g. regarding antiretroviral metabolism and distribution should also be considered as a cause for 
Citation: Theuring S, Mugenyi K, Rubaihayo J, Busingye P, Harms G (2015) Antiretroviral Therapy Programme Retention and Outcomes after 12 Months in a Retrospective Patient Cohort in Fort Portal, Uganda: The Ongoing Challenge of Male ART Performance. J AIDS Clin Res 6 : 423. doi:10.4172/2155-6113.1000423

differing treatment outcomes. In women, higher drug concentrations have been reported as a result of differences in body weight, fat distribution and other factors, leading to better treatment responses [11]. However, drug levels were not measured in this cohort and we could therefore not analyse pharmacodynamic differences. There is a need for further research in this context, so that we will better understand the causes for different treatment outcomes in men and women.

While Ugandan guidelines on ART [23] recommend prophylactic cotrimoxazole intake in all ART patients to avert comorbidities, in our cohort less than half were initiated on it at ART enrollment; patients already presenting with an OI were more likely to receive the antibiotic from the beginning. This could be an indicator for drug shortage leading to selective prescription preferring patients in progressed disease stages; at the same time, it is possible that the full benefit of prophylactic cotrimoxazole intake before the occurance of OIs is not sufficiently communicated to health staff. However, after 12 months, almost three quarters of patients did receive cotrimoxazole.

Retention rates in this cohort after 6 and 12 months were similar to some other studies [16], but higher than in the majority of comparable investigations: Peltzer et al., or Fox and Rosen found an all-cause attrition rate double as high in their South African cohorts $[18,24]$. According to UNAIDS, there is considerable variation in reported retention rates among countries, but data from 18 countries showed that 12 -month retention rates averaged $86 \%$ [1], similar to the rate found in our Ugandan cohort. While lower CD4-cell count at ART enrolment was the only independent risk factor for all-cause 12 months attrition and confirmed death, patients who were LTFU for unknown reason had not presented with significantly lower CD4-cell counts than retained patients. This implies that the majority of patients LTFU for unknown reason could in fact be alive but LTFU for other reasons than death, contradicting previous studies who found $40-60 \%$ mortality in patients LTFU $[6,8]$.

A limitation of this study was the fact that we used retrospective monitoring data, which had been entered not primarily for research purposes. Therefore, several factors which would have been insightful for our analysis, like patients' viral loads, BMI, or pill counts, had not been collected in this routine monitoring system. Also, flawed or missing data entries occured, probably due to high work load of health staff and lacking presence of additional study staff during data collection. Another limitation was the fact that due to low numbers of confirmed death cases, multivariate logistic regression could not be performed to differentiate between influencing factors of confirmed death and LTFU for unknown reason. This analysis would be of specific value for programme planners aiming at bringing patients who are LTFU back into care, and should be targeted in larger cohort studies in the future.

Concluding, in this Ugandan ART cohort, 12 months retention and outcomes were overall encouraging, demonstrating that ART programmes following standardised treatment protocols can be quite successful. Still, one in eight patient who initiated ART in our study setting was lost to care by 12 months. Patients starting ART at progressed disease stage, i.e. with CD4-cell counts below 100 cells/ $\mathrm{mm}^{3}$, were less likely to be alive and in the programme after the first year, with men being the predominant risk goup for late ART initiation. Improvement of ART services therefore needs to include a strong focus on male HIV-positive individuals from the very beginning of the treatment cascade. As Johannessen has put it, men could be the „losers of the antiretroviral treatment scale-up" [15], because, in contrast to women, they lack routine health services which automatically engage them in HIV testing and treatment, but very likely also because of other socio-behavioural reasons. While we need more research in this context to fully understand where the observed gender gaps in ART outcomes derive from, the problem has been known for several years and obviously hasn't been sufficiently addressed. Our study confirms an ongoing strong need to target gender gaps in ART outcomes. It is now a liability for health decision makers and implementers to undertake according steps allowing men to equally partake in the global ART scale-up.

\section{Acknowledgements}

Thanks are owed to Futures Group/AIDSRelief Uganda and the ACT department of the Ugandan Catholic Medical Bureau for supporting the study team in making the data accessible for this analysis. This study was supported through the ESTHER clinic partnership programme of GIZ (Gesellschaft für Internationale Zusammenarbeit, Agency for International Cooperation), Germany.

\section{References}

1. UNAIDS (2013) Global report. UNAIDS report on the global AIDS epidemic 2013.

2. Ministry of Health, Uganda (2011) Uganda AIDS Indicator Survey (UAIS) Prevalence of HIV and Syphilis (cited $24^{\text {th }}$ September 2013).

3. Uganda AIDS Commission (2012) 2014 Progress reports submitted by countries.

4. Government of Uganda, Ministry of Finance, Planning and Economic Development (2013) Millennium Development Goals Report for Uganda 2013.

5. Moore DM, Yiannoutsos CT, Musick BS, Tappero J, Degerman R, et al. (2011) Determinants of early and late mortality among HIV-infected individuals receiving home-based antoretroviral therapy in rural Uganda. J Acquir Immune Defic Syndr 58: 289-296

6. Nakiwogga-Muwanga A, Alamo-Talisuna S, Musaazi J, Kambugu A Ssekawungu P, et al. (2014) Inadequate Monitoring in Advanced Stages of Disease with Lack of Supportive Counseling Increases Attrition among Patients on Antiretroviral Treatment at a Large Urban Clinic in Uganda. J Int Assoc Provid AIDS Care 13: 547-454.

7. WHO (2011) Retention in HIV Programmes. Defining the challenges and identifying solutions. Meeting report 13-15 September 2011, Geneva.

8. 8. Fox M, McCarthy O, Over M (2013) A novel approach to accounting for loss to follow-up when estimating the relationship between CD4 count at ART initiation and mortality. PLoS One 8: e69300.

9. Uganda Ministry of Health (2012) The Integrated National Guidelines on Antiretroviral Therapy 2012

10. Kipp W, Alibhai A, Saunders LD, Senthilselvan A, Kaler A, et al. (2010) Gende differences in antiretroviral treatment outcomes of HIV patients in rural Uganda. AIDS Care 22: 271-278.

11. Hawkins C, Chalamilla G, Okuma J, Spiegelman D, Hertzmark E, et al. (2011) Sex differences in antiretroviral treatment outcomes among HIV-infected adults in an urban Tanzanian setting. AIDS 25: 1189-1197.

12. Cornell M, Schomaker M, Garone DB, Giddy J, Hoffmann CJ, et al. (2012) Gender differences in survival among adult patients starting antiretroviral therapy in South Africa: a multicenter cohort study. PLoS Medicine 9: e1001304.

13. Muula AS, Ngulube TJ, Siziya S, Makupe CM, Umar E, et al. (2007) Gende distribution of adult patients on highly active antiretroviral therapy (HAART) in Southern Africa: a systematic review. BMC Public Health 7: 63.

14. Mills EJ, Bakanda C, Birungi J, Chan K, Hogg RS, et al. (2011) Male gender predicts mortality in a large cohort of patients receiving antiretroviral therapy in Uganda. JIAS 14: 52

15. Johannessen A (2011) Are men the losers of the antiretroviral treatment scaleup? AIDS 25: 1225-1226.

16. Gerdts S, Wagenaar B, Micek M, Farquhar C, Kariaganis M, et al. (2014) Linkage to HIV Care and Antiretroviral Therapy by HIV Testing Service Type in Central Mozambique: A Retrospective Cohort Study. J Acquir Immune Defic Syndr 66: e37-44. 
Citation: Theuring S, Mugenyi K, Rubaihayo J, Busingye P, Harms G (2015) Antiretroviral Therapy Programme Retention and Outcomes after 12 Months in a Retrospective Patient Cohort in Fort Portal, Uganda: The Ongoing Challenge of Male ART Performance. J AIDS Clin Res 6 : 423. doi:10.4172/2155-6113.1000423

17. Tadesse K, Haile F, Hiruy N (2014) Predictors of Mortality among Patients Enrolled on Antiretroviral Therapy in Aksum Hospital, Northern Ethiopia: A Retrospective Cohort Study. PLoS ONE 9: e87392.

18. Peltzer K, Ramlagan S, Khan MS, Gaede B (2011) The social and clinical characteristics of patients on antiretroviral therapy who are 'lost to follow-up' in KwaZulu-Natal, South Africa: a prospective study, SAHARA-J 8: 179-186.

19. Bwambale FM, Ssali SN, Byaruhanga S, Kalyango JN, Karamagi CA (2008) Voluntary HIV counselling and testing among men in rural western Uganda: implications for HIV prevention. BMC Public Health 8: 263.

20. Sekandi JN, Sempeera H, List J, Mugerwa MA, Asiimwe S, et al. (2011) High acceptance of home-based HIV counseling and testing in an urban community setting in Uganda. BMC Public Health 11: 730-730.
21. Choko AT, Desmond N, Webb EL, Chavula K, Napierala-Mavedzenge S, et al. (2011) The Uptake and Accuracy of Oral Kits for HIV Self-Testing in High HIV Prevalence Setting: A Cross-Sectional Feasibility Study in Blantyre, Malawi. PLoS Med 8: e1001102.

22. Nachega JB, Hislop M, Dowdy DW, Lo M, Omer SB, et al. (2006) Adherence to highly active antiretroviral therapy assessed by pharmacy claims predicts survival in HIV-infected South African adults. J Acquir Immune Defic Syndr 43 $78-84$.

23. Uganda Ministry of Health and ICF International (2012) 2011 Uganda AIDS Indicator Survey: Key Findings. Calverton, Maryland, USA: MOH and ICF International.

24. Fox MP, Rosen S (2010) Patient retention in antiretroviral therapy programmes up to three years on treatment in sub-Saharan Africa, 2007-2009: systematic review. Trop Med Int Health 15: 1-15. 